Hanna K. Lappalainen 1,2,10*, Nuria Altimir', Veli-Matti Kerminen',

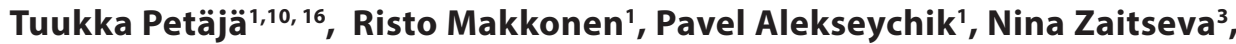
Irina Bashmakova ${ }^{1}$, Joni Kujansuu ${ }^{1}{ }^{16}$, Antti Lauri', Päivi Haapanala', Stephany B. Mazon', Alla Borisova', Pavel Konstantinov ${ }^{4}$, Sergej Chalov ${ }^{4}$, Tuomas Laurila², Eija Asmi², Heikki Lihavainen'2, Jaana Bäck', Michael Arshinov ${ }^{5}$, Alexander Mahura ${ }^{1}$, Steven Arnold ${ }^{6}$, Timo Vihma ${ }^{2}$, Petteri Uotila ${ }^{1}$, Gerrit de Leeuw ${ }^{2}$, IImo Kukkonen ${ }^{1}$, Svetlana Malkhazova ${ }^{4}$, Veli-Pekka Tynkkynen ${ }^{7}$, Irina Fedorova ${ }^{8}$, Hans-Christian Hansson ${ }^{9}$, Sergey Dobrolyubov ${ }^{4}$, Vladimir Melnikov ${ }^{10,11}$, Gennady Matvienko ${ }^{5}$, Alexander Baklanov ${ }^{12}$, Yrjö Viisanen ${ }^{2}$, Nikolay Kasimov ${ }^{4}$, Huadong Guo ${ }^{13}$, Valery Bondur ${ }^{14}$, Sergej Zilitinkevich ${ }^{1,2,4,10,15}$ and Markku Kulmala ${ }^{1,10}$ 'Institute for Atmospheric and Earth System Research INAR / Physics, Faculty of Science, University of Helsinki, Helsinki, Finland

${ }^{2}$ Finnish Meteorological Institute, Helsinki, Finland

${ }^{3}$ Dept. of Earth Sciences, Russian Academy of Sciences, Russia

${ }^{4}$ Faculty of Geography, Lomonosov Moscow State University, Moscow, Russia ${ }^{5}$ Institute of Atmospheric Optics, Russian Academy of Sciences, Tomsk, Russia ${ }^{6}$ Institute for Climate and Atmospheric Science, School of Earth and Environment, University of Leeds, UK

${ }^{7}$ Aleksanteri Institute, Department of Social Research, University of Helsinki, Helsinki, Finland

${ }^{8}$ Institute of Earth Science, OSL, Arctic and Antarctic Research Institute, St.

Petersburg State University, St. Petersburg, Russia

${ }^{9}$ Dept. of Environmental Science and Analytical Chemistry, Stockholm University, Sweden

${ }^{10}$ Department of Cryosphere, Tyumen State University, Tyumen, Russia

${ }^{11 T y u m e n ~ S c i e n t i f i c ~ C e n t e r, ~ S i b e r i a n ~ B r a n c h, ~ R u s s i a n ~ A c a d e m y ~ o f ~ S c i e n c e, ~ T y u m e n ~}$ Russia

${ }^{12}$ World Meteorological Organization, Geneva, Switzerland

${ }^{13}$ Institute of Remote Sensing and Digital Earth, Chinese Academy of Sciences, Beijing, China

${ }^{14}$ AEROCOSMOS Research Institute for Aerospace Monitoring, Moscow, Russia

${ }^{15}$ Department of Radiophysics, Nizhny Novgorod State University, Nizhny Novgorod, Russia

${ }^{16}$ Joint international research Laboratory of Atmospheric and Earth SysTem sciences (JirLATEST), Nanjing University, Nanjing, China

* Corresponding author: hanna.k.lappalainen@helsinki.fi 


\title{
PAN-EURASIAN EXPERIMENT (PEEX) PROGRAM: AN OVERVIEW OF THE FIRST 5 YEARS IN OPERATION AND FUTURE PROSPECTS
}

\begin{abstract}
The Pan-Eurasian Experiment (PEEX) program was initiated as a bottom-up approach by the researchers coming from Finland and Russia in October 2012. The PEEX China kick off meeting was held in November 2013. During its five years in operation, the program has established a governance structure and delivered a science plan for the Northern Eurasian region. PEEX has also introduced a concept design for a modelling platform and ground-based in situ observation systems for detecting land-atmosphere and ocean-atmosphere interactions. Today, PEEX has an extensive researcher's network representing research communities coming from the Nordic countries, Russia and China. PEEX is currently carrying out its research activities on a project basis, but is looking for more coordinated funding bases, especially in Russia and in China. The near-future challenge in implementing the PEEX research agenda is to achieve a successful integration and identification of the methodological approaches of the socio-economic research to environmental sciences. Here we give insight into these issues and provide an overview on the main tasks for the upcoming years.
\end{abstract}

KEY WORDS: multidisciplinary approach, multiscale research, global grand challenges, arctic-boreal environment, observation networks, modelling platform, land-atmosphere interactions, the Arctic Ocean

CITATION: Hanna K. Lappalainen, Nuria Altimir, Veli-Matti Kerminen, Tuukka Petäjä, Risto Makkonen, Pavel Alekseychik, Nina Zaitseva, Irina Bashmakova, Joni Kujansuu, Antti Lauri, Päivi Haapanala, Stephany B. Mazon, Alla Borisova, Pavel Konstantinov, Sergej Chalov, Tuomas Laurila, Eija Asmi, Heikki Lihavainen, Jaana Bäck, Michael Arshinov, Alexander Mahura, Steven Arnold, Timo Vihma, Petteri Uotila, Gerrit de Leeuw, Ilmo Kukkonen, Svetlana Malkhazova, Veli-Pekka Tynkkynen, Irina Fedorova, Hans-Christian Hansson, Sergey Dobrolyubov, Vladimir Melnikov, Gennady Matvienko, Alexander Baklanov, Yrjö Viisanen, Nikolay Kasimov, Huadong Guo, Valery Bondur, Sergej Zilitinkevich and Markku Kulmala (2018) Pan-Eurasian Experiment (PEEX) Program: An overview of the first 5 years in operation and future prospects. Geography, Environment, Sustainability,

Vol.11, No 1, p. 6-19

DOI-10.24057/2071-9388-2018-11-1-6-19

\section{INTRODUCTION}

The Pan-Eurasian Experiment (PEEX) Program (www.atm.helsinki.fi/peex/) is an international, multidisciplinary, multiscale bottom-up initiative. The precursor idea of PEEX, first called as "Pan-Siberian Experiment", was released in 2011. The importance of the
Siberia region and it's boreal (taiga) forests in the climate system was introduced by Kulmala et al. (2011), who emphasized biogenic volatile organic compound (BVOC) emissions from the boreal forest, their connection to secondary aerosol formation process and aerosols in the cloud formation processes and in turn their effect on the radiation balance on 
the Earth surface. Thus, the first idea was to organize a measurement program for aerosols, greenhouse gases (GHG) and BVOCs. It was also discussed that such type of program could serve as a starting point for establishing a more coherent, coordinated observation network extending from Scandinavia to China and with the focus on the understanding processes in the land-atmosphere interface. In 2012, this idea expanded to cover the whole Northern Eurasian geographical domain and evolved into PEEX (Kulmala et al. 2011; Lappalainen et al. 2014, 2015).

\section{GOVERNANCE}

The promoter institutes of the PEEX Program have been the University of Helsinki (UHEL) and Finnish Meteorological Institute in Finland (FMI), Institute of Geography of the Moscow State University, AEROCOSMOS, and Institute of Atmospheric Optics (Siberian branch, the Russian Academy of Sciences (SB RAS)) in Russia, Institute of Remote Sensing and Digital Earth (RADI) of the Chinese Academy of Sciences (CAS) and Institute for Climate and Global Change Research of Nanjing University in China. The program governance and communications are coordinated by the PEEX Offices in Helsinki (PEEX Headquarters), in Moscow, in Beijing and in Nanjing. One of the main tasks of the PEEX Headquarters is to coordinate information flows and distribute information at different scales. In 2018, the PEEX office network is expected to expand and new offices or local contact points will be established Russia in cities of Vladivostok and Tyumen. The upcoming challenge will be the training of the new PEEX science officers to act as local contact points and to establish fluent information flows within the network. The Program Steering Committee consists of internationally recognized central scientists and research directors in their fields, who are overseeing and discussing the position of PEEX program in the international research and research infrastructure landscape. At an institutional level, the collaboration within PEEX is typically initiated by signing a Memorandum of Understanding (MoU) with the PEEX program. Up to this date, we have signed PEEXoriented Memorandum of Understanding (MoUs) with 30 and 5 universities or research institutes in Russia and China, respectively.
As a whole, the PEEX researchers' network includes approximately 4000 researchers from 20 countries in Europe, Russia and China. The network is currently dominated by the experts representing the atmospheric sciences. The near-future challenge in implementing the PEEX research agenda is the identification and integration of the socio-economic and marine researchers into the PEEX research community at a larger scale. The PEEX science conferences are the main forum for the research community to share their scientific outcomes. For the 3rd Science Conference (held in Moscow, September 2017), altogether 181 abstracts were submitted; of which 113 (63\%) represented atmospheric sciences, 24 (13\%) ocean sciences, and 44 (24\%) socio-economics disciplines, including political and epidemiological sciences, research infrastructures $(12 ; 7 \%)$, and university science oriented education $(5 ; 3 \%)$.

In addition to the organization of the conferences, the work of the PEEX working groups (WG) is facilitated by organizing working ground meetings. So far, the ModellingPlatform (MP) WG and the Infrastructure WG have been the most active and their work has been mainly focused on the concept design of the modelling platform and on establishing the PEEX in-situ observation network in Russia. For example, the MP Working Group has almost 100 members from European, Russian, and Chinese institutions including international organizations (ECMWF, WMO) covering different multi-scales and types of models (in total more than 30 models). MP webpages at: https://www.atm.helsinki.fi/peex/index.php/ modelling-platform introduces the modelling platform overview, list of modelling tools and demonstrations, information on past meetings and sessions.

New working groups and community based activity as bottom-up activities are foreseen on topics like "environmental change and epidemics" and "connecting social parameters to atmospheric emissions".

PEEX Headquartes is coordinating the PEEX network at different levels (researchers, institutes and organizations) and the governance activities together with other offices in Russia and in China. This activity is facilitated by different tools such as a website (www.atm.helsinki.fi/peex/), e-news-letter, 
e-mailing lists, social media (Twitter has \#PEEX hashtag), organization of conferences, conference sessions, meetings and forums (e.g. 1st Sofia Earth Forum in Helsinki, 2016). During 2012-2017, we have organized altogether 7 meetings and 3 science conferences (Helsinki - 2015, Beijing - 2016, Moscow - 2017). Starting from January 2017, PEEX has joined the U-Arctic community of 170 Arctic universities; and PEEX acts as an "Arctic-Boreal Hub", which is one of the U-Arctic Thematic networks (www.uarctic. org/organization/thematic-networks/arcticboreal-hub). The Arctic-Boreal Hub network expands the PEEX approach into a circumpolar context and opens up connection points with the US and Canadian research communities. One practical example of this activity was the ARCTIC Fluxes - CRAICC/CRUCIAL (Critical steps in understanding land surface - atmosphere interactions: from improved knowledge to socioeconomic solutions) workshop (February 2017, Hyytiälä, Finland) which was attended by 71 participant from Canada, USA, Europe and Russia. As a whole, the PEEX network is open for new researchers and organizations representing different scientific disciplines to join in and is especially interested in strengthening the role of social and socio-economic sciences within this community.

\section{RESEARCH}

The main scientific mission of the PEEX program is to understand large-scale feedbacks and interactions between the land-atmosphere-ocean continuum in the changing climate of northern high latitude and in China (Kulmala et al. 2016, Lappalainen et al. 2016). The PEEX Science Plan (Lappalainen et al. 2015; http://www.atm.helsinki.fi/peex/ images/PEEX_Science_Plan.pdf) addresses the scientific aims and large-scale research questions of the program (Fig. 1). The focal points in the PEEX research are e.g. on the net effects of various feedback mechanisms connecting the biosphere, atmosphere and human activities. These feedbacks can either hinder or speed up the climate change. Such feedbacks stem from higher temperature and increased concentration of GHG in the future. The climate change and associated feedbacks lead to further consequences, such as permafrost thawing, land cover changes, increased dissolved organic carbon content in freshwaters, acidification of the Arctic Ocean, increased photosynthetic activity, elevated GHG uptake by terrestrial ecosystems, increased BVOCs emissions, changes in secondary aerosol production, changes in cloud processes and their effects on the radiation budget as well as precipitation.

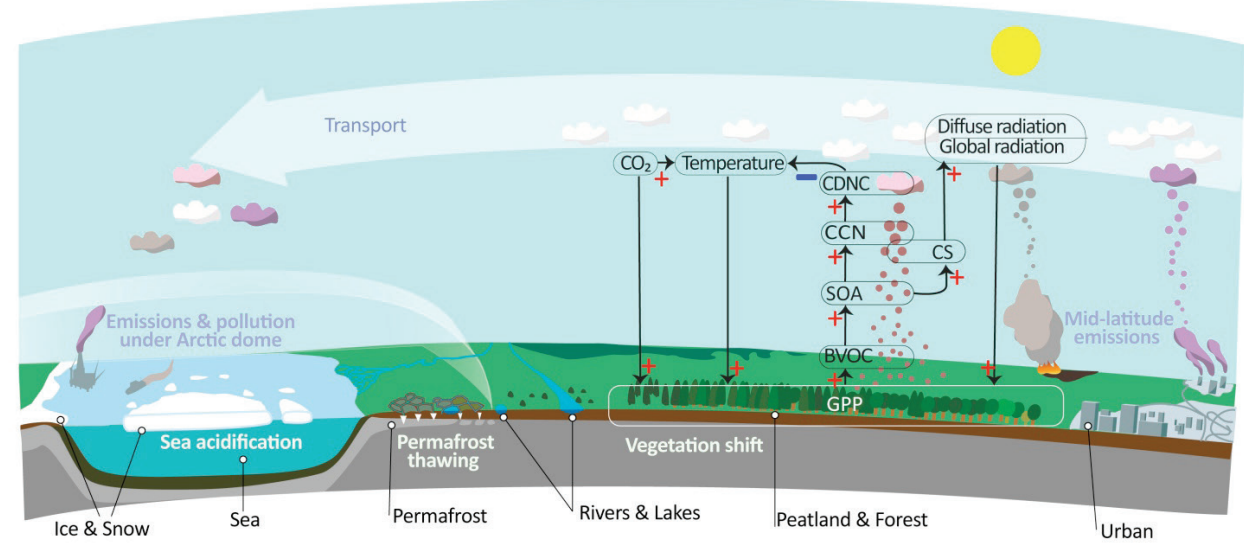

Fig. 1. Overview of the PEEX research domain, which extends over the Eurasian region, from Arctic to Boreal and Temperate zones. The figure lists key processes that drive the research focuses and the variety of site types that come under study. As an example of feedback process, the COBACC (COntinental Biosphere Atmosphere Cloud Climate; Kulmala et al. 2014) feedback mechanism is superposed on the elements of the landscape, evidencing the width of the scale coverage required for its observation 
The backbone of the research approach has been the scientific contribution of the Finnish Center of Excellence in Atmospheric Science - From Molecular and Biological processes to The Global Climate (FCoE-ATM), which delivers about 150-200 peer reviewed papers annually. In addition to FCOE -ATM, a new 5-year European Research Council's Advanced Grant project on "Atmospheric Gas-to-Particle Conversion" and the Academy professorship "Air quality - climate interactions and feedbacks" lead by Academician M. Kulmala will continue the scientific work relevant to the PEEX research agenda. Since 2015, PEEX has been gathering research results on the Arcticboreal environments via the PEEX Special Issue in Atmospheric Chemistry and Physics (ACP) scientific journal (www.atmos-chem-phys.net/ special_issue395.html). Altogether 28 papers in a final form and 10 papers under revision have been published by August 2017. Based on the keywords listed in the papers, the foci of the results has been on the role of boreal forest and their BVOC emissions and subsequent aerosol formation processes (Fig. 2). However, the based on "the degree of participation" and "the amount of collaboration by country" demonstrates an increasing international collaboration and the increasing collaboration between Finland, Russia and China (Fig. 3). The future challenge is to expand the scientific coverage of the published results relevant to the PEEX research agenda and, in practice, initiate the research collaboration with socioeconomic research communities. One of the hot topics here has been the influence of the climatic factors on human health and to study "Climatic factor and epidemics in the context of regional and global environmental changes", "climate and allergy plants flowering", "global warming and possible change of medicalgeographical situation" and "bioclimatic conditions and comfort for living in different regions". Furthermore, PEEX will develop new methods for the visualization of the scientific results in a compact informative form.

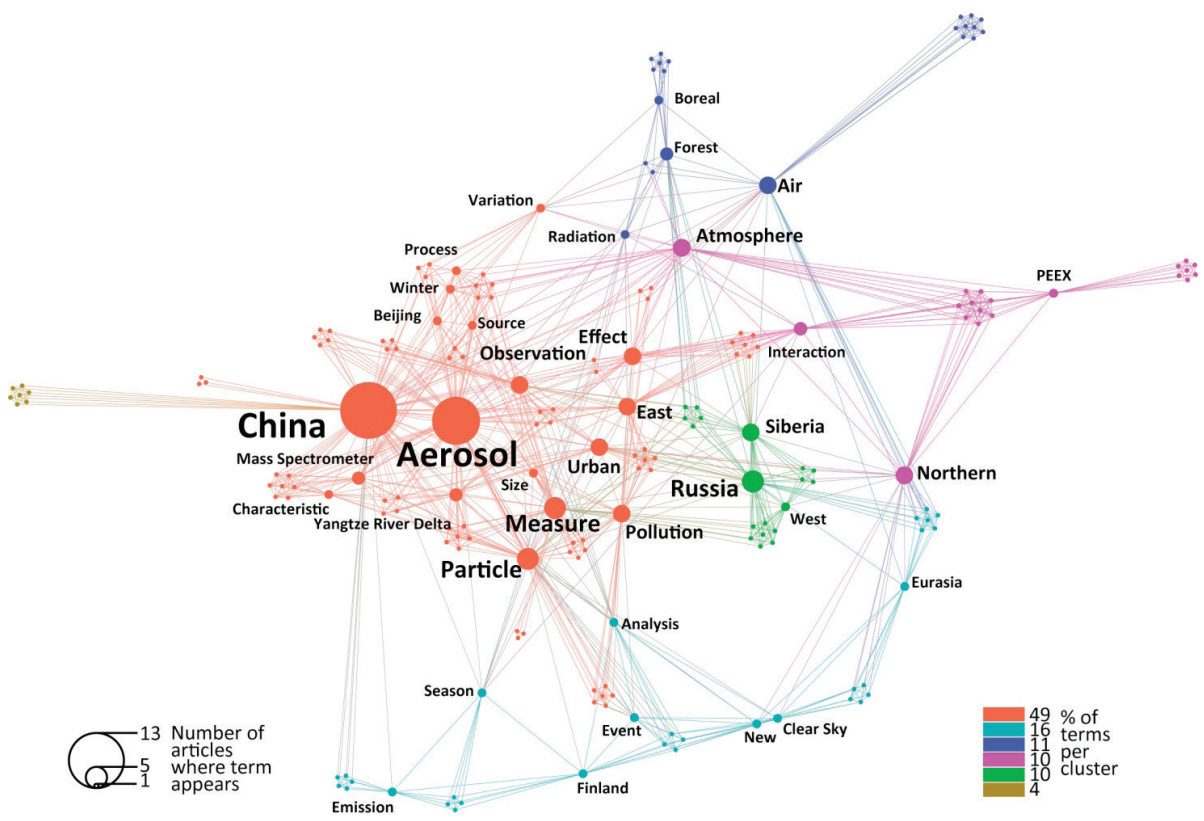

Fig. 2. Overview of the research articles in the ACP PEEX special issue (31 published, as on 9.11.2017). The figure shows the topic coverage as a network of related terms, with labels shown for terms shared by at least two papers. The term source is the titles or the articles; if missing, the country of data generation was added. Terms are single words except in the case where combined expressions appeared always together. Node size is proportional to the occurrence, node position indicates the degree of relation relative to the rest of the nodes, and colours differentiate clusters of more related terms. Analysis made with Sci2 and Gephi 

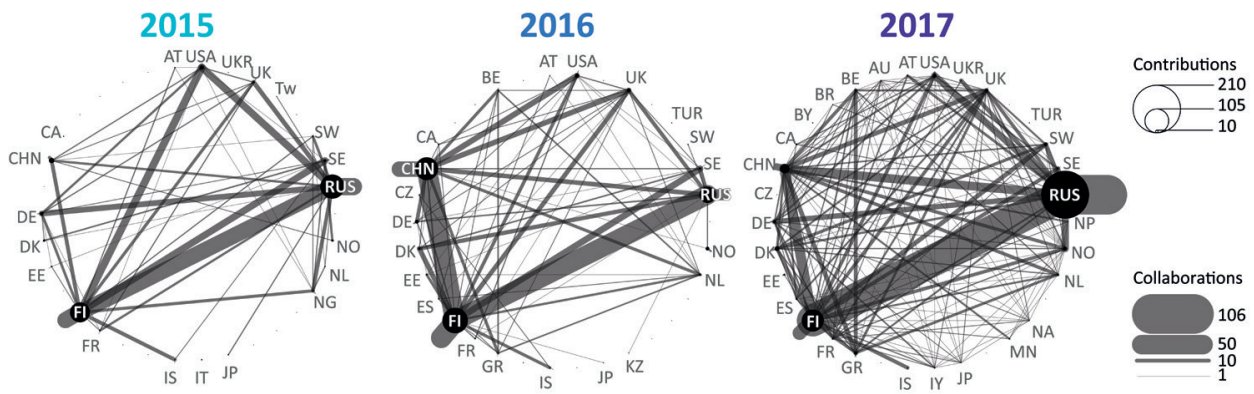

Fig. 3. Degree of participation and the amount of collaboration in the works included in the PEEX conference proceedings, by country. The amount of contributions shows the total times per year that a certain country appears in the affiliation lists. The number or collaborations refers to the times certain two countries are sharing co-authorship. The lines connecting two countries refer to the between-country collaboration, within-country collaborations (that is, different institutes from the same country in the same work) is represented by the lines that go outwards

\section{RESEARCH INFRASTRUCTURE}

Arctic - boreal infrastructure and common data formats

The main strategic challenge of the PEEX program is to initiate a comprehensive and coordinated research infrastructure in collaboration with the main partners in Russia and China. There is an urgent need for comprehensive, coordinated in-situ observations over the Arctic and Northern
Eurasian region detecting different fluxes, emissions and concentrations on greenhouse gases and atmospheric compounds between different Earth surfaces and atmosphere (Fig. 4). In situ observations are providing complementary information to the satellite observations, which provide an overview on a large spatial scale, and both information flows are used together with modeling to create a complete understanding of the processes over the PEEX study area.

Database and data portal
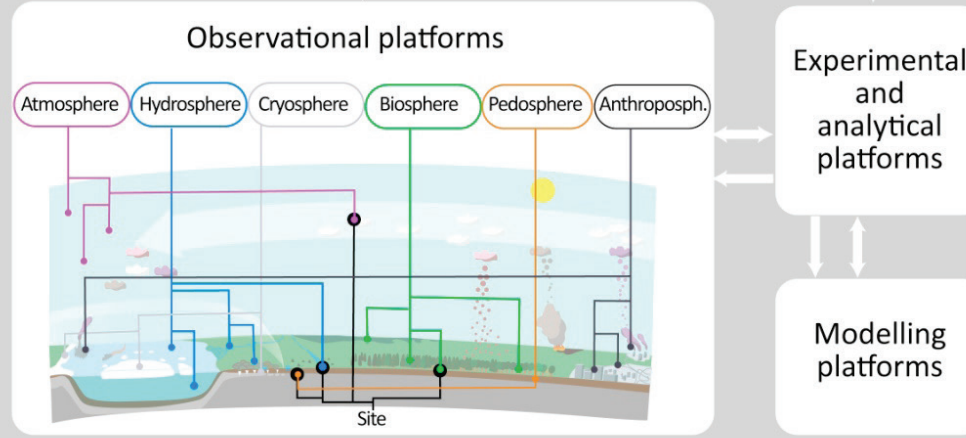

Fig. 4. Overview of the infrastructure conceptual framework. The observational platforms are highly distributed covering all compartments of the system so that multitude of variables are measured for the same compartments and multiple of compartments are measured at one same site. The future task is to establish connections and information flows between each platforms and, in the end, provide atmospheric and environmental real time data for different national early warning systems 
The PEEX land-ecosystem in-situ network will be built upon complementary approaches. The coordination and upgrading of the existing station activities and establishing new SMEAR (Stations for Measuring Earth surface - Atmosphere Relations) -type stations will be based on a SMEAR concept (Hari et al. 2016). The principles of the PEEX in-situ observation network, also as a part of the global observatory, were introduced by Hari et al. (2016) and Kulmala et al. (2016). In reference to the "coordination and upgrading of the existing stations" in Russia, the collection of the preliminary information of the existing station activities started in 2012. The first inventory on more than 200 in situ stations operating in the Arctic and Subarctic Eurasian regions was conducted by the Russian Academy of Sciences (RAS) and Moscow State University together with the University of Helsinki (Alekseychik et al. 2016). Based on the first inventory, we are currently collecting more detailed information, termed "station metadata" here. The station metadata includes detailed descriptions of variables from atmospheric and ecosystem (soil-forest-lake-urbanpeatland-taiga) measurements and from the observation site itself. This enables the categorization of the stations in a systematic manner, and it will provide tools to connect them to international observation networks, such as WMO-Global Atmospheric Watch Program, China Ecosystem Network (CERN) and global SMEAR network, and to carry out standardization work towards common data formats. Based on this work, PEEX will also publish a station e-catalog, which will give information on the on-going measurements and contact points and will initiate research collaboration between the research groups.

One of the most important relevant PEEX research infrastructure activity, focused mainly on Arctic regions, just started under the ERAPLANET (The European network for observing our changing planet) project (www.era-planet.eu) Horizon-2020 project (the Strand-4) "Integrative and Comprehensive Understanding on Polar Environments (iCUPE, www.atm.helsinki.fi/ icupe) and is led by University of Helsinki. The core idea of iCUPE is the development of novel, integrated, quality-controlled and harmonized in-situ observations and satellite data in the polar areas, including also data products for the end users.

In terms of the Arctic marine environment, the most relevant observations for PEEX will be collected from regions of the Russian Arctic, and in particular, the Siberian coastal regions. For this, good quality data on the current state and change of hydrography, sea ice and marine biology are needed. This is issue addressed by the PEEX marine concept, which is, similarly to the SMEAR measurement concept for the land-atmosphere surfaces, based on a hierarchical station network, but affected by the practical challenges in making longterm observations in and over the sea. The processes to be studied include the sea ice thermodynamics and dynamics, ocean heat and freshwater budgets, ocean circulation and hydrography, waves and tides, ocean chemistry and ecosystems, atmospheric heat and moisture budgets, synoptic-scale cyclones and Polar lows, tropospherestratosphere coupling, atmospheric boundary-layer processes, as well as aerosols and clouds (Vihma et al. 2014). An essential aspect of the development and operation of the PEEX marine component is its close linkage to the PEEX land-atmosphere component. Only in this way important research challenges related to the coastal processes, such as river freshwater and heat fluxes, melting of the subsea permafrost and the erosion of shoreline, can be adequately addressed.

The development of the PEEX research infrastructure concepts and identification of the research needs are also connected to the EU Horizon2020-BG-09 "Integrated Arctic Observation Systems" (INTAROS; 20162021; www.intaros.eu) project coordinated by the Nansen Environmental and Remote Sensing Center, Norway; and it contributes to the Arctic Council's Sustainable Arctic Observation Systems Network (SAON).

\section{Modelling Platform}

The purpose of the PEEX Modelling Platfrom (MP) is to support the PEEX observational system and to answer the PEEX scientific 
Table 1. Examples of relevant PEEX hydrospheric research topics and their key gaps.

\begin{tabular}{|l|l|}
\hline Research topic & Key issues \\
\hline $\begin{array}{l}\text { Seasonal tidal maps for } \\
\text { the Siberian Arctic }\end{array}$ & $\begin{array}{l}\text { The lack of marine observations limits the validity of current maps: } \\
\text { need for more measurement sites. }\end{array}$ \\
\hline $\begin{array}{l}\mathrm{CO}_{2} \text { fluxes through the } \\
\text { atmosphere-ocean } \\
\text { interface }\end{array}$ & $\begin{array}{l}\text { Large observational uncertainties exist, e.g. in terms wind velocity } \\
\text { at high latitudes. New high resolution renanalysis products are } \\
\text { likely a part of the solution. }\end{array}$ \\
\hline $\begin{array}{l}\text { Global eddy-resolving } \\
\text { ocean model }\end{array}$ & $\begin{array}{l}\text { Southern Ocean eddies have large impacts on the World Ocean } \\
\text { circulation with decadal oceanic signals propagating to the North } \\
\text { Atlantic sub-polar gyre, and occasionally to the Arctic Ocean. } \\
\text { Hence, one should ideally have a global eddy-resolving ocean } \\
\text { model to derive oceanic boundary conditions for Arctic climate } \\
\text { simulations. }\end{array}$ \\
\hline $\begin{array}{l}\text { Freeze-up and melt } \\
\text { times of Siberian lakes }\end{array}$ & $\begin{array}{l}\text { Very relevant for the Northern Eurasian region and could be used } \\
\text { to build a map of observed regional climatic trends and variability. } \\
\text { The map could be complemented spatially with remote sensed } \\
\text { data. }\end{array}$ \\
\hline $\begin{array}{l}\text { Long series } \\
\text { constructed from river } \\
\text { catchment flow data }\end{array}$ & $\begin{array}{l}\text { River runoff data could provide long-term time series of variability } \\
\text { for many climatic zones. They could also be used to estimate } \\
\text { transports of carbonand chemical fluxes. However, river regulation } \\
\text { may affect the quality of time series. }\end{array}$ \\
\hline $\begin{array}{l}\text { Methane ems } \\
\text { from tundra lakes }\end{array}$ & $\begin{array}{l}\text { Are not well studied and the existing data have high uncertainties. } \\
\text { Furthermore, climatic change affects the fluxes. To obtain a } \\
\text { more comprehensive view, emissions from wetlands and peats } \\
\text { should be included. Existing measurement time series need to be } \\
\text { maintained. Combination with remote sensing measurements } \\
\text { would provide an extended spatial coverage. Short targeted field } \\
\text { campaigns are also necessary, and could be associated with the } \\
\text { PEEX education component. }\end{array}$ \\
\hline
\end{tabular}

questions, which requires a hierarchy and a framework of modern multi-scale models for different elements of the Earth system integrated with the observation system. The PEEX-MP provides a seamless approach that considers several dimensions of the coupling between temporal and spatial scales, a wide range of processes, Earth system components, types of observations and modelling tools, useroriented integrated systems and impact based forecasts and services (Baklanov et al. 2017). In particular, the temporal scales are ranging from minutes (e.g. nowcasting) to decadal and centennial (climate change), while the spatial scales are varying from the regional to a global scale (dowscaling and upscaling). Processes can be of physical, chemical, biological, social or some other character, and they can be occurring in the atmosphere, hydrosphere, pedosphere, biosphere or in other environments. The PEEX-MP models will be validated and constrained by available in-situ and remote sensing data of various spatial and temporal scales.

The MP will be based on a seamless modelling framework from nano-scale modelling to global Earth System Models (ESMs). It will also introduce community-based services for data mining and for demonstrating air pollution events at regional scales. One of the large-scale components of PEEX-MP consists of the EC-Earth ESM (www.ec-earth. org), which combines all relevant PEEX elements (atmosphere-ocean-sea-ice) on the global scale. Downscaling approach is 
realized with the Enviro-HIRLAM (seamless online integrated coupled meteorologychemistry-aerosols) modelling system, which can be subsequently run on hemispheric-regional-subregional-urban scales by producing simultaneously 3D meteorology and atmospheric composition (Baklanov et al. 2017). For example, for large eddy simulations (LES), the UCLALESSALSA (Tonttila et al. 2017), PALM, and LESNIC models can be used for large scale applications with sectional aerosol module included, for simulations of atmospheric and oceanic flows, and for simulation of stably stratified planetary boundary layer, respectively (Esau 2014).

The overall list of MP models is available at https://www.atm.helsinki.fi/peex/index. $\mathrm{php} / \mathrm{modelling-tools-demonstration,} \mathrm{where}$ each model has a short description and information on available modes for the model runs, components and processes, which are covered by the model and corresponding list of references. A series of models/ modules is available in PEEX-MP framework. These models can be used to simulate organic compounds, sulfuric acid and aerosols; surface energy in urban or natural environments and water balance; tropospheric gas-phase and aerosol physical and chemical processes at multiple scales; atmosphere-vegetation interactions; coupling of the atmosphere, ocean and land surface through the exchange of energy, momentum, water and important trace gases; and coupling of the ocean and sea ice at various scales. There are also processbased models for simulating methane emissions from natural/ managed wetlands; crop photosynthesis, respiration and other processes involved in crop growth and carbon/ nitrogen dynamics in soils; hydrobiogeochemical gaseous carbon and nitrogen emissions and hydrologic nitrogen losses from a catchment; biosphereatmosphere-hydrosphere exchange processes at site, local, and regional scales, etc. Finally, there are MP models in support of research on atmospheric circulation and composition from global to local scales; inverse modeling of GHG emissions; atmospheric transport, dynamics, dispersion and deposition at global-hemispheric- regional-other scales for air pollution and climatic environmental studies; and inverse modeling with data assimilation framework.

The key issues for the PEEX modelling framework are anthropogenic emissions; permafrost effects; carbon dioxide and methane; ecosystem carbon cycle; short lived pollutants and climate forcers; BVOC emissions; forest fires and their effects; aerosol formation in Arctic and Siberia; aerosol radiative forcing; air pollution ecosystem feedbacks; dynamics of ocean and sea ice; and high impact events.

\section{EDUCATION}

Within PEEX we have recognized the need of discipline-tied fundamental education as a backbone for multidisciplinary research. However, also shift towards multidisciplinarity in education is imperative for a successful career in climate and global change science (Nordic Climate Change Research 2009). Based on the experiences in educating several generations of students during the past 20 years in the Nordic research community, we have developed a model to improve the learning outcomes in multidisciplinary atmospheric sciences. The model is a result of work including pedagogical experiments, utilization of modern technologies (Junninen et al. 2009), workshops for teachers and supervisors and, most importantly, organizing a long series of multidisciplinary hands-on researchintensive short courses for graduate students.

During the last 5 years, Division of Atmospheric Sciences of University of Helsinki has been coordinating the following international environmentaleducation projects responding to new challenges posed by PEEX an funded by the EU-Commission: TEMPUS 159352-FIJPHES "Development of qualification framework in meteorology" (2010-2013); Erasmus+ 561975-EPP-1-2015-1-FI-EPPKA2CBHE-JP "Adaptive learning environment for competence in economic and societal impacts of local weather, air quality and climate (2015-2018, www.e-impact.net). 
The PEEX community has been actively involved in organizing special events, such as Young Scientist Summer Schools (YSSS); research training intensive courses on modelling, observations and data analysis; and the series of education workshops in the framework of InterCarto conferences. During such events, young researchers have the opportunity to attend lectures and participate in practical exercises showing their personal skills in doing research. For that, for example, practical exercises are developed as independent small-scale research projects (Mahura et al. 2012). Such approach is problem-based learning (Duch et al. 2001). The schools were organized in 2008, 2011 and 2014 in Zelenogorsk, Russia (led by NordForsk NetFAM; netfam.fmi. fi), in Odessa, Ukraine (led by NordFOrsk MUSCATEN; muscaten.ut.ee), and in Aveiro, Portugal (by EU COST Action EuMetChem; eumetchem.info; Baklanov, 2017). The main focus of these schools was on-online integrated modelling of meteorological and chemical transport processes for weather, air quality, and climate applications.

Besides the YSSSs, the Nordic research community has run a dedicated multidisciplinary master's programme ABS (Atmosphere-Biosphere Studies) continuously since 2006. A special feature of the ABS programme is the continuous series of short research-intensive interdisciplinary courses. Five to ten such courses are currently given every year.

The PEEX partners are setting up new programs as well. Recent examples of these are POMOR, a master's program for applied and marine sciences at St. Petersburg State University, Russia; CORELIS, Cold Regions Environmental Landscapes Integrated Science program; and the Russian-Chinese MSc program in hazard hydrological events. Furthermore, there have been projects to foster Russian-Nordic collaboration in developing education, such as the NordicRussian University Network for Successful Cooperation in Higher Environmental Education and the Nordic-Russian Virtual University Campus for Higher Environmental Education. The NordForsk-funded CRUCIAL project paves way for the multidisciplinary
PEEX education activities. The EU-funded ECOIMPACT Erasmus+ program project (e-impact.net/en) is developing sectoral courses in a personal learning environment. Earlier, the PEEX community carried out two TEMPUS projects, COMBAT-METEO and QUALIMET.

The PEEX education roadmap includes the following main components: (i) labeled and themed research-intensive international interdisciplinary short courses; (ii) introduction of a dedicated Pan-Eurasian mobility programme for MSc and PhD students and postdocs; (iii) development of new educational tools based on pedagogical research done in the PEEX community; (iv) development of joint online courses and massive open online courses (MOOCs); (v) sharing good practices and benchmarking done in dedicated PEEX education workshops; and (vi) encouraging partners to seek for bilateral funding to develop education and to increase mobility.

\section{CONCLUSIONS}

As a whole, the Pan-Eurasian Experiment is an active contributor and a collaborator in the international research and research infrastructure landscape. The main international partners and collaborators are the Future Earth and Future Earth iLEAPS, Arctic Council AMAP and SAON WGs, GEO - GEOSS Cold regions (PEEX the in situ observations activity), U-Arctic, IIASA and WMO GAW program. PEEX is also closely connected to International Eurasian Academy - European Center and the DBAR (Digital Belt and Road) Initiative, which are interested to provide a big data platform on Earth observation from China and countries along the new Silk Road - Belt and Road area. PEEX has released a program agenda and is currently finalizing the conceptual design of PEEX-relevant research infrastructures. The program is currently calling for financial support from the European Union, Russian and Chinese basic funding organizations to implement the program at a large scale. The implementation of the PEEX program would make significant impact on the sustainable development of the Northern societies and China. 


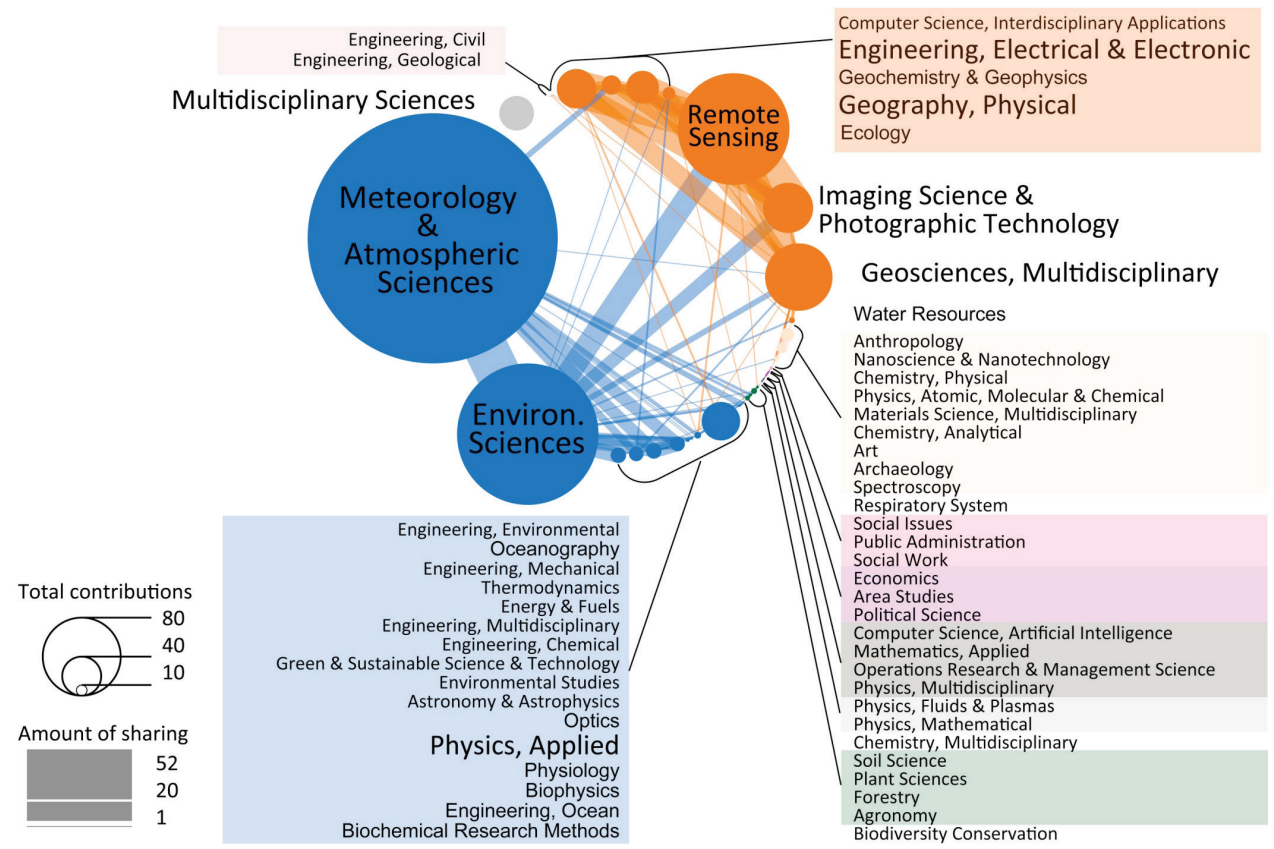

Fig. 5. Future potential of the research community in different scientific disciplines could be demonstrated by the published papers between 2012 and present for 8 active PEEX researchers. Data mined form Web-of-Science Classification of "Research areas" according to Web-of-Science, "Research areas" is an attribute to the journal where the paper was published. A journal can belong to more than one Research area

\section{ACKNOWLEDGEMENTS}

A major part of the PEEX Preparatory Phase work in years 2010-2017 has been based on the in-kind contribution of several European, Russian and Chinese research institutes via supporting active participation to the PEEX meetings, conference organized in Helsinki, Moscow, Hyytiälä, Saint Petersburg and Beijing. In addition we would like acknowledge the following support or funding from the following bodies: Finnish Cultural Foundation, Grant: Prof. Markku
Kulmala "International Working Groups"; Russian Mega-Grant No. 11.G34.31.0048 (University of Nizhny Novgorod), Academy of Finland contract 259537, Beautiful Beijing (Finland- China collaboration project) funded by TEKES, EU project InGOS and the NordForsk Nordic Centre of Excellence of CRAICC (no 26060), Nordforsk CRAICCPEEX (amendment to contact 26060) and Nordforsk CRUCIAL-project active in 20162017. ERAPLANET iCUPE, Academy of Finland (FCOE), European Commission (ACTRIS). 


\section{REFERENCES}

Alekseychik P., Lappalainen H.K., Petäjä T., Zaitseva N., Heimann H., Laurila T., Lihavainen H., Asmi E., Arshinov M., Shevchenko V., Makshtas A., Dubtsov S., Mikhailov E., Lapshina E., Kirpotin S., Kurbatova Yu., Ding A., Guo H., Park S., Lavric J.V, Reum F., Panov A., Prokushkin A., and Kulmala M. (2016). Ground-based station network in Arctic and Subarctic Eurasia: an overview. J. Geography Environment Sustainability, No 2, pp. 75-88.

Arneth A., Harrison S. P., Tsigaridis K., Menon S., Bartlein P. J., Feichter H., Korhola A., Kulmala M., O'Donell D., Schurgers G., Sorvari S., Vesala T., and Zaehle S. (2010). Terrestrial biogeochemical feedbacks in the climate system: from past to future. Nat. Geosci., 3, pp. 525-532.

Baklanov A. (2017). Overview of the European framework for online integrated air quality and meteorology modelling (EuMetChem). Atmospheric Chemistry and Physics, doi:10.5194/acp-special_issue370-preface.

Baklanov A., Smith Korsholm U., Nuterman R., Mahura A., Sass B., Rasmussen A., Zakey A., Kaas E., Kurganskiy A., Sorensen B., and González-Aparicio I. (2017). The Enviro-HIRLAM online integrated meteorology-chemistry modelling system: strategy, methodology, developments, and applications. Geosci. Model Dev. Discuss. 10.5194/gmd-2016-319.

Duch B. J., Groh S. E. and Allen D. E. (2001). The Power of Problem-Based Learning. Stylus Publishing, Sterling, VA, U.S.A.

Esau I. (2004). Simulation of Ekman Boundary Layers by Large Eddy Model with Dynamic Mixed Subfilter Closure. Environmental Fluid Mechanics 4: 273-303.

Hari P., Petäjä T., Bäck J., Kerminen V-M., Lappalainen H.K. Vihma T., Laurila T., Viisanen Y., Vesala T., and Kulmala M. (2016). Conceptual design of a measurement network of the global change. Atmos. Chem. Phys., 16, pp. 1017-1028.

Hari P., Andreae M. O., Kabat P., and Kulmala M. (2009). A comprehensive network of measuring stations to monitor climate change. Boreal Environ. Res., 14, pp. 442-446.

Hari P. and Kulmala M. (2005). Stations for Measuring Ecosystem - Atmosphere Relations (SMEAR II). Boreal Environ. Res., 10, pp. 315-322.

Junninen H., Lauri A., Keronen P., Aalto P., Hiltunen V., Hari P., and Kulmala M. (2009). Smart-SMEAR: on-line data exploration and visualization tool for SMEAR stations. Boreal Environment Research, 14, pp. 447-457.

Kulmala M., Nieminen T., Nikandrova A., Lehtipalo K., Manninen H. E., Kajos M.K., Kolari P., Lauri A., Petäjä T., Krejci R., Hansson H-C., Swietlicki E., Lindroth A., Christensen T.R., Arneth A., Hari P., Bäck J., Vesala T., and Kerminen V-M. (2014). CO2-induced terrestrial climate feedback mechanism: From carbon sink to aerosol source and back. Boreal Environment Research 19 (suppl. B): pp. 122-131.

Kulmala M., Lappalainen H.K., Petäjä T., Kerminen V-M., Viisanen Y., Matvienko G., Melnikov V., Baklanov A., Bondur V., Kasimov N., and Zilitinkevich S. (2016). Pan-Eurasian Experiment (PEEX) Program: Grant Challenges in the Arctic-boreal context. J. Geography Environment Sustainability., 2, pp. 5-18, DOl:http://dx.doi.org/10.15356/2071-9388_02v09_2016_01. 
Kulmala M., Lappalainen H.K., Petäjä T., Kerminen V-M., Viisanen Y., Matvienko G., Melnikov V., Baklanov A., Bondur V., Kasimov N., and Zilitinkevich S. (2016). Pan-Eurasian Experiment (PEEX) Program: Grant Challenges in the Arctic-boreal context. J. Geography Environment Sustainability, 2, pp. 5-18.

Kulmala M., Lappalainen H.K., Petäjä T., Kurten T., Kerminen V-M., Viisanen Y., Hari P., Bondur V., Kasimov N., Kotlyakov V., Matvienko G., Baklanov A., Guo H., Ding A., Hansson H-C., and Zilitinkevich S. (2015). Introduction: The Pan-Eurasian Experiment (PEEX) - multidisciplinary, multi-scale and multi-component research and capacity building initiative. Atmos. Chem. Phys., 15, 13085-13096, doi:10.5194/acp-15-13085-2015.

Lappalainen H.K., Petäjä T., Kujansuu J., KerminenV-M., Shvidenko A., Bäck J., Vesala T., Vihma T., De Leeuw G., Lauri A., Ruuskanen T., Lapshin V.B., Zaitseva N., Glezer O., Arshinov M., Spracklen D.V., Arnold S.R., Juhola S., Lihavainen H., Viisanen Y., Chubarova N., Chalov S., Filatov N., Skorokhod A., Elansky N., Dyukarev E., Esau I., Hari P., Kotlyakov V., Kasimov N., Bondur V., Matvienko G., Baklanov A., Mareev E., Troitskaya Y., Ding A., Guo H., Zilitinkevich S., and Kulmalas M. (2014). Pan Eurasian Experiment (PEEX) - A research initiative meeting the Grand Challenges of the changing environment of the Northern Pan-Eurasian arcticboreal areas. Geography, Environment, Sustainability, 7(2):13-48.

Lappalainen H.K., Kulmala M., and Zilitinkewich S. (2015). Pan-Eurasian Experiment (PEEX) Science Plan. Helsinki 2015. ISBN 978-951-51-0587-5 (printed).

Nordic Climate Change Research (2009). NordForsk Policy Briefs 2009-8. Mandag Morgen.

Tonttila J., Maalick Z., Raatikainen T., Kokkola H., Kühn T., and Romakkaniemi S. (2017). UCLALES-SALSA v1.0: a large-eddy model with interactive sectional microphysics for aerosol, clouds and precipitation. Geosci. Model Dev., 10, 169-188, https://doi.org/10.5194/ gmd-10-169-2017. 


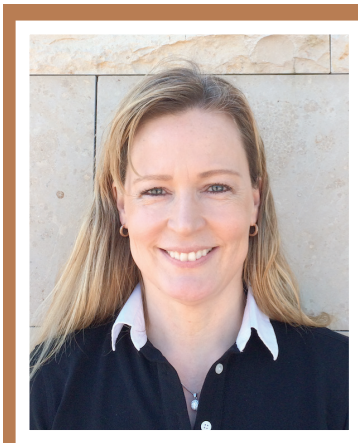

Hanna K. Lappalainen, PhD, Pan-Eurasian Experiment (PEEX) Program Secretary General, works currently at PEEX Headquarters, at the University of Helsinki, Institute for Atmospheric and Earth System Research (INAR). She has a long-term experience of coordinating large-scale research projects and funding applications and has been working as a research coordinator and a science coordinator of large scale projects at the Finnish Centre of Excellence in Physics, Chemistry, Biology and Meteorology of Atmospheric Composition and Climate Change (2012-2013). Since 2014 Lappalainen has been a representative of Finland in the Sustainable Arctic Observing Network (SAON) Data working group, a Future Earth - iLEAPS Steering Group Member and starting from 2017 as a national delegate of the International Arctic Science Committee (ISAC) - The International Science Initiative in the Russian Arctic (ISIRA). She obtained her PhD. from the Department of Biological and Environmental Sciences, University of Helsinki, Finland and has been engaged in analysis of the atmospheric concentration of the Biogenic Volatile Organic Compounds (BVOCs) and plant phenological time series and modelling. 